REVIEW ARTICLE

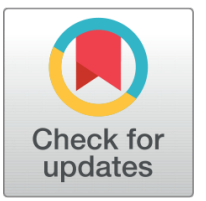

open access

Received: 18.11 .2020

Accepted: 25.11 .2020

Published: 03.12 .2020

Citation: Purohit S, Jain AK (2020) Technological transition from analog to internet of things ( IoT ) on Indian petro-retail's customer service. Indian Journal of Science and Technology 13(42): 4364-4368. https ://doi.org/10.17485/IJST/v13i42.1964

* Corresponding author.

purohits13@gmail.com

Funding: None

Competing Interests: None

Copyright: @ 2020 Purohit \& Jain. This is an open access article distributed under the terms of the Creative Commons Attribution License, which permits unrestricted use, distribution, and reproduction in any medium, provided the original author and source are credited.

Published By Indian Society for Education and Environment (iSee)

ISSN

Print: 0974-6846

Electronic: 0974-5645

\section{Technological transition from analog to internet of things ( IOT ) on Indian petro-retail's customer service}

\author{
Santanu Purohit ${ }^{1 *}$, Arvind Kumar Jain ${ }^{1}$ \\ 1 School of Business, University of Petroleum \& Energy Studies, Dehradun, India
}

\section{Abstract}

Objectives: To identify the gap in the adaptation of IoTs towards meeting the customer expectation for services in petro-retailing in India. Method: Review of available published research articles, case studies, published article in journals and websites on uses of IOTs in various sectors like retail, telecom manufacturing, supply chain management, oil \& gas etc. Findings: Technological advances have had a significant impact on both consumers as well as industries. While internet changed the way human interact, Internet of Things (IOT) is expected to change the way machines interact. Adding a networked layer to regular objects has transformed the way we use and interact with them. Industries like healthcare, manufacturing, telecom, etc have seen significant changes with the introduction of loT. Oil \& Gas industry has also seen implementation of IOT but the adoption has varied according to sector. Upstream sector, involved in exploration and drilling, has seen significant adoption while Mid-stream sector, involved in transport and storage, has seen only specific application. IoT solutions have been used for cost optimization as well as improved operations management. Downstream sector (including refining and retail) has seen only limited adoption. Novelty: IoTs are the technology on which future society is going to ride. The use of IoT is going to have huge impact in service industry including petro retailing. Hence the analysis of gap in adaptation shall be helpful for the academician's, managers in Oil \& Gas industry for further review, study and implementation.

Keywords: Internet of Things; Indian fuel retail; IOT in oil \& gas; new technology adoption; customer experience

\section{Introduction}

Technology has impacted industries in multiple ways, bringing innovation and creating great value for the society. Technology's impact may be clubbed as radical, incremental, disruptive or architectural. James Watt's steam engine heralded the $1^{\text {st }}$ industrial revolution while computers led the most recent. However, it was the advent of Internet which fundamentally changed how we interact - with the world as well as each other. There are similar expectations from the latest (fourth) era - Internet of Things (IoT). IoT maybe best understood as a network of physical objects, connected via sensors, 
software, and other technologies for the purpose of connecting and exchanging data online so as to enable enhanced services and applications. IoT has applications in various sectors like health, automobile, education, etc. Internet of things is becoming a revolution in the current scenario. In fact, it is changing the very interaction between objects and human. There are a wide range of IoT applications from smart wearables, smart homes at a personal level to smart city, etc. at a societal level. It has greatly improved the quality of lifestyle for consumers.

The Internet of Things (IoT), which basically integrates sensing, communications, and analytics capabilities, has been evolving for some time now. But it is nearing maturity now, as the core enabling technologies have improved to the point that its widespread adoption seems likely. IoT's promise lies not merely in helping Oil \& Gas companies directly manage their existing assets, supply chains, or customer relationships-rather, IoT technology creates an entirely new asset: information about these elements of their businesses.

According to McKinsey, global gas demand is expected to reach 4,503 billion cubic meters (bcm) in 2035, showing a more than $1 \%$ annual growth from $3,736 \mathrm{bcm}$ in 2017 . Asia is expected to be the biggest consumer of the resource at $47 \%$, followed by the rest of the world (24\%), the Middle East (16\%), and the United States (14\%). AI and the internet of things (IoT) have found their way into the oil and gas world. IoT is the technology that allows devices, machinery, and other equipment to communicate with each other. It enables oil and gas companies to manage and store data, create applications, and set security protocols using data science methodologies. IOT along with the usage of Artificial Intelligence (AI) and enabled edge computing shall help in predictive maintenance in plants i.e. in upstream, mid-stream and in refineries ${ }^{(1)}$.

\subsection{IOT in Oil \& Gas context}

Some of the major challenges faced by executives in the Oil \& Gas value chain include (i) aging equipment and legacy systems, (ii) hazardous environment and (iii) growing competition \& increasing regulatory oversight. Today's technology has great potential to not only solve these challenges, but also enhance performance in this field. IoT application in the oil and gas sector includes usage of sensors, smart algorithm, predictive \& preventive maintenance, etc. While robots, drones and wearables are the approaches getting the most attention and investment, IoT serves as a basic foundation for continuous monitoring and analysis of data. In this regard, the application of IoT technologies in oil and gas monitoring systems makes a significant difference. Given the recent advances in sensor technology as well as increasing connectivity options, the management in the oil and gas industry can monitor anything in real-time, from the changing seabed topography, chemical composition of crude oil to the integrity of a gas pipeline and tanker fleet positioning. The enhanced capabilities of IoT-based monitoring systems can be applied throughout the oil and gas supply chain - upstream, midstream and downstream. Further, the deployment of IoT also enables usage of advanced data analytics and visualization tools. Management can use convenient dashboards to track operations and read the latest measurements on PC or mobile, from the comfort of one's office or home, and respond to changes remotely using actuators and controls in real-time. Remote monitoring helps workers reduce repeat on-site visits. Performing routine manual checks are not the only benefits of using IoT for oil and gas production and distribution, which (i) enable real-time equipment, fleet and environmental conditions monitoring, and provide better transparency and control over processes, (ii) allow for timely on-demand equipment maintenance and optimize related cost and effort, (iii) ensure better worker safety and transfer risky onsite operations to robots and UAVs, (iv) introduce automation, including automated leakage and breakage control, (v) reduce the negative environmental impact associated with oil and gas production and distribution and (vi) optimize manpower and cut down on non-productive time and downtime ${ }^{(2)}$.

For the Oil \& Gas (O\&G) industry, the advantages of IoT applications lie in creating value through an integrated deployment strategy. IoT will allow the industry to digitize, optimize, and automate processes that were previously unconnected to save time, money, and increase safety. IOT can add value in following areas: (i) Remote Services: IOT can be used to get real time data, information in upstream industry to predict break down or scheduled maintenance activities, (ii) Predictive and Preventive Maintenance: can be used for at upstream, middle stream and downstream facilities, especially at storage locations, (iii) Health and Safety: accidents can be very costly. By deploying IoT- enabled safety measures, O\&G companies will not only keep their employees safe but benefit from a decrease in corporate liability and an increase in profit, (iv) Asset Tracking and Monitoring: tracking sensors provide useful information so that Companies can better identify inventories. If an item is missing, an IoT system can be used to track shipments with the exact location of each oil and gas asset, (v) Data Management: Data management and analytics from the oilfields, pipelines, refineries, and other energy sites, are crucial to the success of the O\&G industry. Data plays a significant role in improvements, such as increasing uptime and recovery rates, making better decisions, and enhancing refining capacity ${ }^{(3)}$.

Study has revealed that with connected IOT solutions companies can (i) lower the cost through increased automation and monitoring of remote processes, (ii) Increase workplace safety and ensure environmental protection through collection of realtime sensor data and conditions, (iii) Increase operational efficiency through more accurate billing, loss prevention and better 
maintenance strategies including off-shore equipment and (iv) increase reliability and longevity of equipment through remote monitoring and data collection ${ }^{(4)}$.

Ample scope for IOT usage has already been identified in upstream and mid-stream, while limited uses have been found in downstream sector storage locations at different models such as (i) server based tank monitoring for real time equipment performance and inventory levels at storage locations, (ii) pipeline asset management etc, (iii) Digital replicas of physical assets simplify change analysis including improved maintenance operations and (iv) Seismic sensors aid oil explorations ${ }^{(5)}$.

Usage of IOT in Oil \& Gas industry was focused on high level architecture - on what IOT can bring to the oil \& gas industry. IOT based smart energy solutions results in better field communication, reduced cost of maintenance, real time monitoring, digital oil field infrastructure, reduced power consumption, mine automation, greater safety \& security of assets and thus higher productivity. IOT solutions can improve efficiency in various areas such as (i) Operational Excellence in field of predictive maintenance, pipeline and equipment monitoring, location intelligence, emission monitoring control and (ii) Operations improvement by way of real time machine \& server integration, real time alert, link to ERP data to trigger maintenance workflow, plan dashboard \& trend analysis, asset information network and fleet operations monitoring. Two aspects i.e. scalability and Security should be considered during the architecture of IOT solution. Cloud based architecture can help eliminate the constraints on account of increasing users and data growth in future ${ }^{(6)}$.

It has also been observed that IOT can optimize production and infrastructure equipment life span in oil \& gas companies. With respect to the field of exploration / production, IOT solutions are already being used by $35 \%$ organizations and $25 \%$ are planning to do so within 2 years. Deployment of sensors or devices to increased data points that will help perform a better job is as important as completely new discoveries. In case of usage of IOT for optimization, there are plenty opportunities for usage of IOT in production and equipment optimization. Well maintenance (in oil \& gas exploration) is one of the examples of the benefits of IOT, and helps in predictive maintenance activities using data available from IOT at remote places ${ }^{(7)}$.

IOT use-cases in Oil \& Gas industry have been demonstrated in the areas of (i) Offshore Oil \& Gas Rig monitoring, (ii) Refinery monitoring, (iii) Pipeline monitoring, (iv) Oil \& Gas cargo shipping, and (v) Supply chain management. Analysis of IOT application in Oil \& gas industry shows that Upstream implementation is used to analyze equipment, track maintenance schedule and prevent malfunctioning, middle stream implementation towards environmental monitoring and regulatory compliance, whereas downstream application is for enabling distribution with real-time oversight ${ }^{(8)}$.

Study has showed that there are 5 ways where IOT can rejuvenate Oil \& Gas industry, and these are (i) Improved Operational Efficiency, (ii) Revenue, (iii) Real Time data, (iv) Decreased safety risk and (v) Environmental foot prints ${ }^{(9)}$.

Three emerging business objectives for usage of IOT in Oil \& Gas industry are (i) Improving reliability (ii) Optimizing Operations and (iii) Creating new value ${ }^{(10)}$.

\subsection{IOT other than Oil \& Gas context}

In the telecom industry, Internet of Things (IoT) may proliferate for many years ahead in India and globally. Industry experts from Vodafone, Tata Communications, Parallel Wireless, L\&T Tech and Accenture paint a picture of numerous future use cases of IoT in India. IoT technology has the potential to transform India in multiple areas like agri-sector, safe water distribution network $^{(11)}$.

In the manufacturing industry, innovative IOT applications are being used in broadly three categories: (i) Smart manufacturing: for continuous monitoring of critical assets, equipment, process, and product parameters within the factory, using sensors with wired networks or Wi-Fi, (ii) Connected products: for products giving continuous feedback about their location and performance after they are put into service in the field by using telemetry for remote monitoring and (iii) Connected supply chain: for keeping track of inbound and outbound shipments for location related information and critical in-transit parameters such as temperature ${ }^{(12)}$.

It has also been observed that IOT is confined to isolated areas in supply chain management (SCM). Further, there is limited availability of solid frameworks \& models that can address the problems in SCM. Moreover, there are several barriers to implementation of IoT in SCM, from both technological and managerial perspectives ${ }^{(13)}$.

\subsection{IOT: Oil \& Gas downstream context}

Oil \& Gas major British Petroleum re-imagined the future of fuel stations via implementation of Machine Learning (ML) and IOT at fuel stations in European and American markets in order to offer the next level of customer experience in self-service, with an AI assistant at site, etc ${ }^{(14)}$.

A study on the implementation of IOT at fuel stations in India showed that this can increase the operational efficiency with respect to accuracy, service quality, cost, security and time consumption ${ }^{(15)}$. 
A mobile app-based application was developed and studied towards creating IOT-based smart petrol station in India. The app was developed to track nearby fuel stations using geo-location ${ }^{(16)}$.

IOT-based fuel station alert systems have also been tried to determine the probable design for generating alerts in case of theft of fuel and introduction of security matrix for appropriate communications ${ }^{(17)}$.

The experimental work in setting up intelligent \& smart fuel stations helped provide operators easy access for fuel management and monitoring of fuel price trends through web interface ${ }^{(18)}$.

Usage of IOT in the downstream sector demonstrated that Consumers expect convenience, reliability and safety from products and services. IoT is expected to have an impact on almost every sphere of operations of Oil and Gas companies. IoT can help create a vibrant and successful ecosystem through the convergence of Operations Technology (OT) and IT (Information Technology). IoT is a connected and disruptive technology which is redefining the ways of doing business and enabling new models of revenue generation. It also helps in improving operations efficiency and pipeline integrity ${ }^{(19)}$.

Multiple factors have contributed to the IoT adoption at Indian Oil Marketing Companies' (OMC) fuel stations. Of these, 5 factors - People, Technologies, Processes, Data Security, and Competitive Advantage, are important to transform the existing retail outlets (RO) into "smart pumps", and to fully realize the expected benefits from the investment in $\mathrm{IoT}^{(20)}$.

\section{Findings \& Discussion}

While upstream companies (engaged in exploration and production) are focused on optimization, and can gain new operational insight by analyzing diverse sets of data, Mid-stream companies (engaged in transportation activities via pipelines \& storage) are eying higher network integrity and new commercial opportunities for significant benefit by building a data enabled infrastructure. Downstream players such as petroleum product refiners and retailers see the most promising opportunities in revenue generation by expanding their visibility into the hydrocarbon supply chain and targeting digital consumers through new forms of connected marketing. Higher cost optimization requires a change in the industry's approach to technology - from using operational technologies to locate and exploit complex resources to using information thus derived to make hydrocarbon extraction, and every successive stage before the sale, more efficient and even more revenue generating. It has also been observed that IOT deployment should be linked to specific business priorities, which can be broadly described under three categories of increasing scope (a) Improve reliability (minimize the risks of HSSE by reducing disruption), (b) Improve cost \& capital efficiency of operation by increasing productivity and optimizing the supply chain and lastly (c) Create new Value (enhance scope, to explore new sources of revenue and competitive advantages that can transform the business).

IOT promises to turn most objects into a source of information about the object. It creates a new way to differentiate products and services, and to create value from the information - "The Information Value Chain". In the upstream sector, assimilating diverse data sets is becoming easier with the deployment of thousands of new sensors and improved handling of the increased complexity. In the Mid-stream sector, enhancing pipeline safety is in all players' interest, since a spill by any single operator can lead to higher costs and tighter regulations for the entire industry. Ensuring safety and minimizing risks are two different activities in the midstream sector. A midstream company would likely accrue a large competitive and commercial advantage if it analyzes product and flow data more comprehensively along its entire network. The "midstream majors" are well positioned to create insights from this new data of volumes because of their diverse portfolio and integrated network. At the same time, in the down-stream sector, Crude-oil refining is a mature business with few recent innovations in processing technology. This, and the highly commoditized nature of petroleum products, make refining the most commercially challenging part of the energy value chain.

Usage of IOT is higher in the upstream sector, mainly for exploration \& production. Remote service, predictive \& preventive maintenance, asset tracking \& monitoring, health \& safety aspects as well as data management, are being taken care with the help of IOT solutions deployed at the Wells \& Rigs.

Implementation of IOT in Supply Chain Management (SCM) is limited to specific areas. In case of manufacturing industry, usage of IOT can led to the excellence in smart manufacturing and connect the product \& supply chain. This can lead to the revenue maximization with associated benefits.

The rapid innovation and proliferation of consumer personal-communication technologies-smart handheld devices and telematics systems in a vehicle-have led to the emergence of connected consumers who, by extension, are demanding a connected fueling experience. The interface is required to be designed as an augmented behavior complementing natural human decision processes or it risks being rejected by consumers as "dictatorial," "strange," or "disrupting". In the future, retail marketing can correlate consumer profiles with fuel purchases and in-store purchases across a retailer's owned stations and franchisees, mash up existing petro-cards data with the data collected by cloud-enabled emerging telematics solutions, and combine data from multiple sources such as status updates and notifications from social-media networks to facilitate behavioral marketing and predictive analytics. Majority of IoT-derived benefits for an integrated refiner/marketer can come from connected marketing. 
In Indian petro-retailing scenario, studies have shown that there is need to implement IOT solutions for fulfilling the customer expectation via enhanced service quality, leading to realization of benefits and maximizing the return on investments.

\section{Conclusion}

Rapid technological advancements as well as increasing exposure to digitization have led to increasing adoption of digital technologies, including IOT. IOT has seen strong adoption in healthcare and manufacturing industries. Globally, telecom industry is also using numerous IOT solutions for improved services. In the oil \& gas context, IOT is being used primarily in the upstream sector for remote monitoring, planning \& executing predictive and preventive maintenance, ensuring safety parameters etc. In the mid-stream sector, IOT adoption has been observed for ensuring network integrity, environmental monitoring and regulatory compliance. There has been very limited research into the usage of IOT in the downstream sector - primarily in refineries and storage \& handling facilities. Globally, there is almost minuscule research into the usage of IOT in the field of safety \& customer services in petro-retailing. In case of Indian petro-retailing, adoption of IOT is negligible, especially from a customer service perspective, in spite of its necessity for delivering better service and maximizing returns. Given the increasing role of technology in consumer lifestyle, there is a need for IOT adoption for improving customer services, to enhance service quality which in turn can provide enhanced safety \& security and revenue maximization. Thus, a clear gap exists in adoption of IOT to meet customer expectation for services. This merits further detailed study into the adoption of IOT solutions for meeting customer expectations and preferences in the Indian fuel retail context.

\section{References}

1) Internet of Things in the Oil and Gas Industry - Current Applications, EMERJ. 2019. Available from: https://emerj.com/ai-sector-overviews/internet-ofthings-oil-and-gas/.

2) IOT Revolution in Oil and Gas Industry, Internet of Things Oil and Gas Monitoring Systems-Digiteum. 2019. Available from: https://www.digiteum.com/ category/iot.

3) Shannon L. IoT Applications in the Oil and Gas Industry. 2019. Available from: https://www.iotforall.com/iot-applications-oil-and-gas-industry.

4) Ready to transform Your Oil and Gas Distribution Business. Oil and Gas IOT Solutions, Sierra Wireless. . Available from: https://www.sierrawireless. com/applications/energy/oil-and-gas/.

5) Internet of Things in Oil and Gas, Deloitte US. . Available from: https://www2.deloitte.com/us/en/pages/consulting/articles/iot-digital-oil-and-gas.html.

6) Rekha K. Usage of Internet of things (IoT) in Oil And Gas Industry - Wipro. . Available from: https://www.wipro.com/en-IN/applications/usage- of-iotin-oil-and-gas/.

7) Bedel C. The State of IoT in the Oil and Gas Industry. 2020. Available from: https://www.iotworldtoday.com/2020/01/31/the-state-of-iot-in-the-oiland-gas-industry/.

8) IOT Solution to transform Oil and Gas Industry, Hiotron. . Available from: https://www.hiotron.com/iot-in-oil-and-gas/.

9) Prakash C. 5 Ways IIoT Will Revolutionize the Oil and Gas Industry. 2018. Available from: https://www.iotforall.com/iiot-in-oil-gas-industry.

10) Deloitte Insights. Connected Barrels: Transforming Oil and Gas strategies with the Internet of Things, The Internet of Things in the Oil and Gas industry. 2015. Available from: https://www2.deloitte.com/us/en/insights/focus/internet-of-things/iot-in-oil-and-gas-industry/.

11) Tina G. IOT use cases: Future picture: Why India will need Internet of Things to bring in major transformation ET Telecom. 2017. Available from: https://telecom.economictimes.indiatimes.com/news/.

12) Ramachandran S, IDC Manufacturing Insights. Innovative Use Cases for the Adoption of Internet of Things in India Manufacturing. 2015. Available from: www.idc.com.

13) Mohamed BD, Elkafi H, Zied B. Internet of things and supply chain management: a literature review. International Journal of Production Research. 2019;57:4719-4742. Available from: https://www.tandfonline.com/doi/full/10.1080/00207543.2017.1402140.

14) BP is reimaging fuel stations with machine learning and IOT. . Available from: https://www.wired.com/wiredinsider/2019/12/bp-reimagining-fuelstations-machine-learning-and-IOT.

15) Megha H, Sini P, V. Internet of Things (IoT) Enabled Automation: A Shift towards Smart Fuel Stations. International Journal of Engineering Science and Computing. 2019;9(4):21332-21335. Available from: http://ijesc.org.

16) Akarsh G. IOT Based Smart Petrol Pump Finder. International Journal of Innovative Research in Computer and Communication Engineering. 2016;4(6):11725-11731. Available from: https://doi.org/10.15680/IJIRCCE.2016.0406134.

17) kumar PN, Kumaresan P, Sundaresan YB. IoT based retail automation of fuel station and alert system. IOP Conference Series: Materials Science and Engineering. 2017;263. Available from: https://dx.doi.org/10.1088/1757-899x/263/4/042072.

18) Punit G, Patodiya S, Singh D, Chhabra J, Shukla A. IoT based Smart Petrol Pump. Fourth International Conference on Parallel, Distributed and Grid Computing (PDGC). 2016. Available from: https://doi.org/10.1109/PDGC.2016.7913168.

19) Sudip D, Shailendra KP, Jos FG, Chandra PD. Internet of Things in the Oil and Gas Industry. International Journal of Engineering and Management Research. 2016;6(4). Available from: https://doi.org/10.1080/1097198X.2019.1679588.

20) Sudip D. The Early Bird Catches the Worm-First Mover Advantage through IoT Adoption for Indian Public Sector Retail Oil Outlets. Journal of Global Information Technology Management. 2019;22(4):280-308. Available from: https://www.ijemr.net/IJEMR/Arch.aspx?rep=42. 